\title{
Structural Behavior of Reinforced Concrete Hybrid Wide Beams under Shear Effect
}

\author{
Ra'id Fadhil Abbas \\ PhD, Lecturer, Civil Engineering Department, Al-Mustansiriyah University, Baghdad, Iraq
}

\begin{abstract}
The present work contains experimental study for the structural performance of reinforced concrete wide beams made from two grades of concrete (32.6 and 63.7 MPa) subjected to shear effect. The specimens involve ten wide beams of dimensions $1200 \times 220 \times 110 \mathrm{~mm}$. The wide beams were divided into two groups according $(\mathrm{a} / \mathrm{d}) \mathrm{ratio}$, the first group are of $(\mathrm{a} / \mathrm{d})$ ratio (2.5) and the second group are of $(\mathrm{a} / \mathrm{d})$ ratio (3.5). The first wide beam in each group is normal strength concrete, the second sample is high strength concrete while the third beam is made from normal strength concrete at top and high strength concrete at bottom, the fourth sample is made from high strength concrete at top and normal strength concrete at bottom, the last beam is divided in to three sections, the mid section from normal strength concrete while the sides from high strength concrete. All the tested wide beams were reinforced with $4 \varphi 8 \mathrm{~mm}$ longitudinal bars in bottom and $2 \varphi 5 \mathrm{~mm}$ in top without web reinforcement. In both groups, comparing to first beam, the second beam exhibits greater ultimate load by about $(42.8 \%$ and $41 \%)$ respectively, the third beam show increasing in ultimate load by $(8.5 \%$ and $5.26 \%)$ while the fourth beam denote increasing in ultimate load by (19\% and $15.8 \%)$, finally, the increasing in ultimate load of the fifth beam is about (33.3\% and 32.6\%). Wide beams made totally or partially from high strength concrete show larger deflection values than the reference beams. Crack width values at service and final stages were recorded. All the tested wide beams were failed in shear.
\end{abstract}

Keywords: wide beams; shear effect; High Strength Concrete; hybrid beams.

DOI: $10.7176 /$ CER/12-11-05

Publication date: November $30^{\text {th }} 2020$

\section{1- Introduction}

In the design of buildings, modern architectural constraints are pushing engineers to provide longer clear spans at a reasonable cost. At the same time, there is a need to minimize the overall structural depth, which can be achieved through the use of wide beams or thick structural slabs. When thick slabs are used, the time savings in construction due to the simplicity of formwork, reinforcement placement, and access by following trades can significantly enhance the cost effectiveness of the overall project [1]. In buildings such as warehouses, commercial buildings, parking garages, and office buildings, to reduce floor height and facilitate the run of services under the floor, reinforced concrete wide beams with a width-depth ratio of at least 2 are used. The seismic performance of wide beams was investigated by Stehle et al., Benavent-Climent, and Gentry and Wight with some recommendations to use these members in seismic regions [2]. Many researches have been conducted to investigate the behavior of wide beam, most of these researches studied the spacing of web reinforcing legs and the region of support connected with column. According to the results of these researches, it can be concluded that the presence of wide beams for various regions and purposes is limited. There are some guidelines on wide beam properties and design in codes such as ACI 318[3] and Eurocode 2[4], where many of these guidelines are not directly proposed for these beams. In fact, most of them refer to the special cases of beams or slabs, which are concert with wide beams [2].

\section{2- Research Significant}

As beam-slab floor systems become shallower, wide reinforced concrete beams are being used to directly carry applied loads or serve as transfer girders in the framing scheme. Making beams wider than the column width is a good way to avoid congestion between longitudinal beam and column corner bars. According to above significant, the structural behavior of reinforced concrete hybrid wide beams under shear effect was studied in the present research. Therefore, this work may be helpful to provide a new data for this important structural member, then getting some suggestions that are useful in construction fields.

\section{3- Experimental Program}

The experimental program consists of testing ten simply supported reinforced hybrid concrete wide beams designed to fail in shear effect which have the same dimensions, the overall length of $1200 \mathrm{~mm}$, a width of 220 $\mathrm{mm}$ and a height of $110 \mathrm{~mm}$. The beams were divided into two groups according to shear span to depth ratio (a/d), each group contains five beams; the first group is tested with making (a/d) ratio equal to (2.5) while the second group is of (a/d) ratio equal to (3.5). The first wide beam in each group is made of normal strength concrete with compressive strength about(32.6 MPa), the second sample is casted from high strength concrete with compressive 
strength about(63.7 MPa), while the third beam is made from normal strength concrete and high strength concrete at top and bottom respectively, fourth sample is made from high strength concrete at top and normal strength concrete at bottom, while last beam is divided into three sections, the mid section is from normal strength concrete while the sides sections are from high strength concrete. The tested wide beams were reinforced with $4 \varphi 8 \mathrm{~mm}$ $(\rho=1.01 \%)$ longitudinal bars in bottom and $2 \varphi 5 \mathrm{~mm}(\rho=0.198 \%)$ in top without web reinforcement. The Table (1) shows the details of the tested wide beams.

\section{4- Materials and Mix Proportions}

In the present research, ordinary Portland cement (type I) and natural fine aggregate (sand) with $4.75 \mathrm{~mm}$ maximum size and crushed coarse aggregate (gravel) with $10 \mathrm{~mm}$ maximum size are used for the production of the concrete mixes. For high strength concrete, a superplasticizer admixture is used to achieve the workability required for vibration and placing. Table (2) shows quantities for production of one cubic meter of concrete.

\section{5- Steel Reinforcing Bars and wood molds}

Two different deformed steel bars were used in the manufacturing of the tested wide beams, the first steel bars are used with nominal diameters of $8 \mathrm{~mm}$ in tension side (four bars) and $5 \mathrm{~mm}$ in compression side (two side bars) for longitudinal reinforcement without stirrups except two of $3 \mathrm{~mm}$ plain bar stirrups at each side used for fixing the bars as shown in Fig. (1). The laboratory tensile tests on bars showed that the average yield stress for $8 \mathrm{~mm}$ diameter was $588 \mathrm{MPa}$ and for $5 \mathrm{~mm}$ diameter was $607 \mathrm{MPa}$. Fig. (2) shows the plywood molds that used to cast the tested beams.

\section{6- Hardened Mechanical Properties Results}

In table (3) the test results of mechanical properties for hardened concrete was recorded. The properties are compressive strength of concrete $\left(f_{c}^{\prime}\right)$, splitting tensile strength $\left(f_{t}\right)$ and modulus of rupture $\left(f_{r}\right)$. Three specimens were tested for each property and the average values were presented in this table.

Table (1) Details of tested wide beams

\begin{tabular}{|c|c|c|c|c|c|c|}
\hline Group & Beam name & $\begin{array}{l}\text { Dimensions } \\
\quad(\mathrm{mm})\end{array}$ & $\begin{array}{c}\rho \% \\
\text { (tension side) }\end{array}$ & $\begin{array}{c}\text { Compressive } \\
\text { strength } \\
(\mathrm{MPa}) \\
\end{array}$ & $\begin{array}{c}\text { Concrete beam } \\
\text { type }\end{array}$ & $\begin{array}{l}\mathrm{a} / \mathrm{d} \\
\mathrm{ratio}\end{array}$ \\
\hline 1 & B1 & $1200 * 220 * 110$ & 1.01 & 32.6 & normal & 2.5 \\
\hline 1 & B2 & $1200 * 220 * 110$ & 1.01 & 32.6 & high & 2.5 \\
\hline 1 & B3 & $1200 * 220 * 110$ & 1.01 & 32.6 & $\frac{\text { normal }}{\text { high }}$ & 2.5 \\
\hline 1 & B4 & $1200 * 220 * 110$ & 1.01 & 32.6 & $\begin{array}{l}\text { high } \\
\text { normal }\end{array}$ & 2.5 \\
\hline 1 & B5 & $1200 * 220 * 110$ & 1.01 & 32.6 & High-normal-high & 2.5 \\
\hline 2 & B6 & $1200 * 220 * 110$ & 1.01 & 63.7 & normal & 3.5 \\
\hline 2 & B7 & $1200 * 220 * 110$ & 1.01 & 63.7 & high & 3.5 \\
\hline 2 & B8 & $1200 * 220 * 110$ & 1.01 & 63.7 & $\frac{\text { normal }}{\text { high }}$ & 3.5 \\
\hline 2 & B9 & $1200 * 220 * 110$ & 1.01 & 63.7 & $\frac{\text { high }}{\text { normal }}$ & 3.5 \\
\hline 2 & B10 & $1200 * 220 * 110$ & 1.01 & 63.7 & High-normal-high & 3.5 \\
\hline
\end{tabular}

Table (2) Quantities of materials for one cubic meter of concrete

\begin{tabular}{|l|c|c|c|c|c|}
\hline \multicolumn{1}{|c|}{ Material } & Cement $(\mathrm{kg})$ & Sand $(\mathrm{kg})$ & Gravel $(\mathrm{kg})$ & Water( liter) & superplasticizer \\
\hline Normal strength concrete & 400 & 600 & 1200 & 150 & - \\
\hline High strength concrete & 550 & 700 & 1000 & 155 & 10 liter \\
\hline
\end{tabular}


Table (3) Tests results of mechanical properties for hardened concrete

\begin{tabular}{|l|r|c|c|}
\hline \multicolumn{1}{|c|}{ property } & $\mathrm{f}_{\mathrm{c}}^{\prime}(\mathrm{MPa})$ & $\mathrm{f}_{\mathrm{t}}(\mathrm{MPa})$ & $\mathrm{f}_{\mathrm{r}}(\mathrm{MPa})$ \\
\hline Normal strength concrete & 32.6 & 2.95 & 3.91 \\
\hline High strength concrete & 63.7 & 4.26 & 5.89 \\
\hline
\end{tabular}

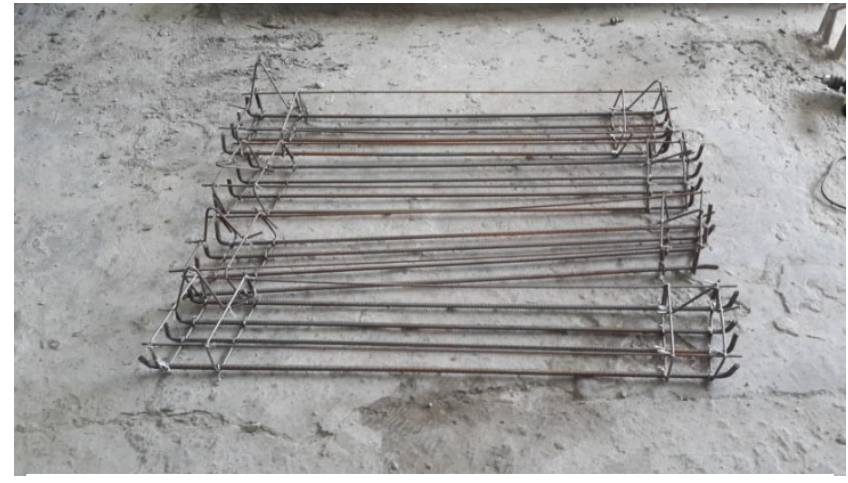

Figure (1) Steel reinforcement for the samples

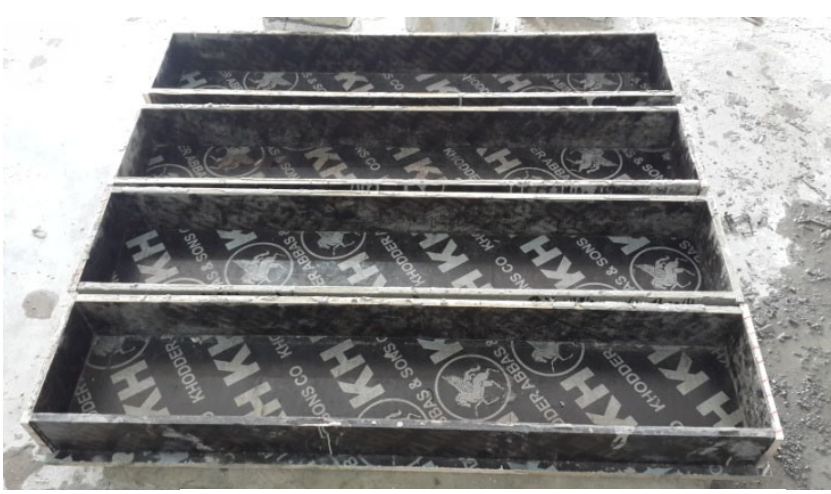

Figure (2) plywood molds

\section{7- Tests and Measurements of Slabs}

In the present research, the wide beams were tested using a hydraulically universal testing machine(8551 M.F.L. system) of capacity $3000 \mathrm{kN}$ up to ultimate load in the Structural Laboratory of the Faculty of Engineering of University of Mustansiriyah as shown in Fig. (3).

For group one, the load was applied by two line loads through two steel rods with distance $650 \mathrm{~mm}$ between them at mid of beam span (the distance from the support face to load arm is $225 \mathrm{~mm}$ ). For group two, the load was also applied by two line loads through the same steel rods but with distance $470 \mathrm{~mm}$ between them at mid of beam span (the distance from the support face to load arm is $315 \mathrm{~mm}$ ). The vertical deflection is measured at mid of wide beam span using dial gauge of accuracy $(0.01 \mathrm{~mm})$ as shown in Fig. (4). Loading increments was read at about $2.5 \mathrm{kN}$. At each reading the deflection value was recorded. When the first shear crack appears, the load corresponding to it was recorded also. The shear crack width was measured at cracking and ultimate stages using digital microscope shown in Fig. (5).

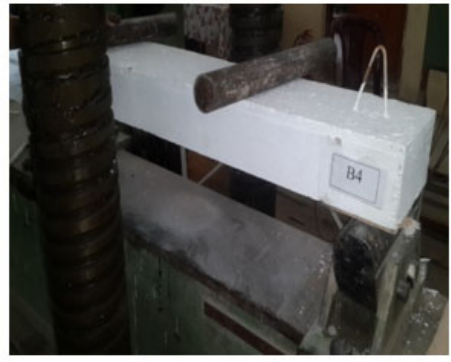

Figure (3) Test setup

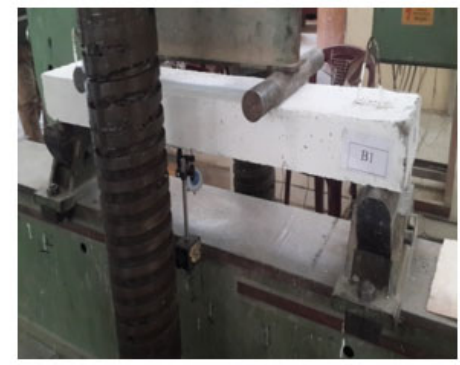

Figure (4) Dial gauge position

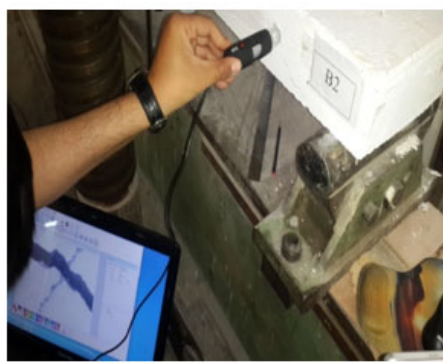

Figure (5) Digital microscope

\section{8- Results data}

The results of the tested wide beams is summarize in Table (4), the results including first shear cracking load ( $\left.\mathrm{P}_{\mathrm{cr}}\right)$, ultimate load $\left(\mathrm{P}_{\mathrm{u}}\right)$, reduction ratio in $\mathrm{P}_{\mathrm{cr}}$ and $\mathrm{P}_{\mathrm{u}}$ due to increasing of a/d ratio between the two groups and cracks width in the cracking and ultimate stages. 
Table (4) Results of Tested Slabs

\begin{tabular}{|c|c|c|c|c|c|c|c|c|c|c|}
\hline $\begin{array}{c}\text { Beam } \\
\text { Name }\end{array}$ & $\begin{array}{c}\mathrm{P}_{\mathrm{cr}} \\
\mathrm{kN}\end{array}$ & $\begin{array}{c}\text { Reduction } \\
\text { in }\left(\mathrm{P}_{\mathrm{cr}}\right) \%\end{array}$ & $\begin{array}{c}\mathrm{P}_{\mathrm{u}} \\
\mathrm{kN}\end{array}$ & $\begin{array}{c}\text { Reduction } \\
\text { in }\left(\mathrm{P}_{\mathrm{u}}\right) \%\end{array}$ & $\frac{\mathrm{P}_{\mathrm{cr}}}{\mathrm{P}_{\mathrm{u}}}$ & $\begin{array}{c}\Delta_{\mathrm{cr}} \\
\mathrm{mm}\end{array}$ & $\begin{array}{c}\Delta_{\mathrm{u}} \\
\mathrm{mm}\end{array}$ & $\frac{\Delta_{\mathrm{cr}}}{\Delta_{\mathrm{u}}}$ & $\begin{array}{c}\text { Crack } \\
\text { width in } \\
\text { cracking } \\
\text { stage } \\
(\mathrm{mm})\end{array}$ & $\begin{array}{c}\text { Crack } \\
\text { width in } \\
\text { ultimate } \\
\text { stage } \\
(\mathrm{mm})\end{array}$ \\
\hline B1 & 25 & - & 52.5 & - & 0.476 & 2.7 & 6.2 & 0.435 & 0.078 & 2.864 \\
\hline B2 & 54 & - & 75 & - & 0.720 & 7.0 & 11.3 & 0.619 & 0.065 & 3.451 \\
\hline B3 & 37 & - & 57 & - & 0.649 & 3.0 & 7.4 & 0.405 & 0.120 & 4.390 \\
\hline B4 & 46 & - & 62.5 & - & 0.736 & 4.3 & 7.9 & 0.544 & 1.136 & 2.338 \\
\hline B5 & 51 & - & 70 & - & 0.728 & 5.4 & 8.6 & 0.628 & 0.205 & 2.966 \\
\hline B6 & 21 & 16 & 47.5 & 9.5 & 0.442 & 2.1 & 4.9 & 0.428 & 0.076 & 3.875 \\
\hline B7 & 39 & 28 & 67 & 10.6 & 0.582 & 5.3 & 8.4 & 0.631 & 0.132 & 1.352 \\
\hline B8 & 30 & 19 & 50 & 12.3 & 0.600 & 4.3 & 7.4 & 0.581 & 0.070 & 2.348 \\
\hline B9 & 35 & 24 & 55 & 12 & 0.636 & 2.9 & 7.0 & 0.414 & 0.054 & 2.131 \\
\hline B10 & 37.5 & 25 & 63 & 10 & 0.595 & 4.6 & 9.0 & 0.511 & 0.136 & 0.218 \\
\hline
\end{tabular}

\section{9- Results Discussion}

\section{9-1 First Cracking Loads}

From Table (4), it can be noted that the increasing of shear span to depth (a/d) ratio from 2.5 to 3.5 reduces first cracking load as clearly shown in group 2 . The reduction is larger when using high strength concrete in the tested wide beams. The observed maximum reduction is (28\%) was in wide beam (B7) in compared with wide beam (B2). The reduction was slightly decreases with using normal strength concrete in the samples.

\section{9-2 Ultimate Loads}

According to Table (4), it can be concluded that the increasing of shear span to depth (a/d) ratio from 2.5 to 3.5 reduces ultimate load as shown in group 2 compared to group 1. The reduction is larger when using high strength concrete in this stage also. The observed maximum reduction is $(12.3 \%)$ was in wide beam (B8) in compared with wide beam (B3). The reduction was of the same range when using normal or high strength concrete in the tested beams. Figures (6) and (7) show the load - deflection response for Group 1 and 2 respectively.

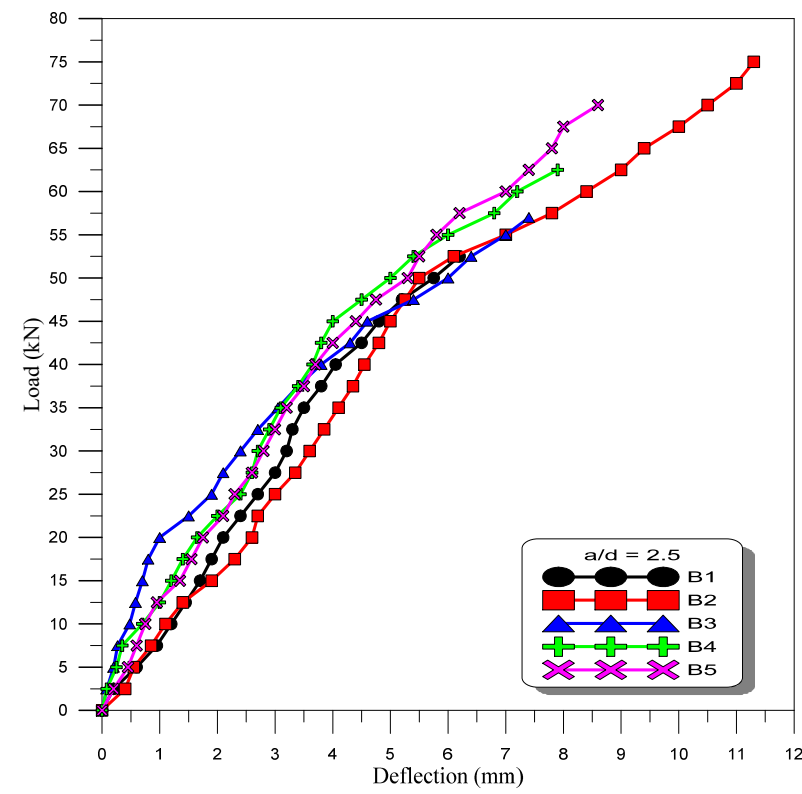

Figure (6) load-deflection curves for Group 1

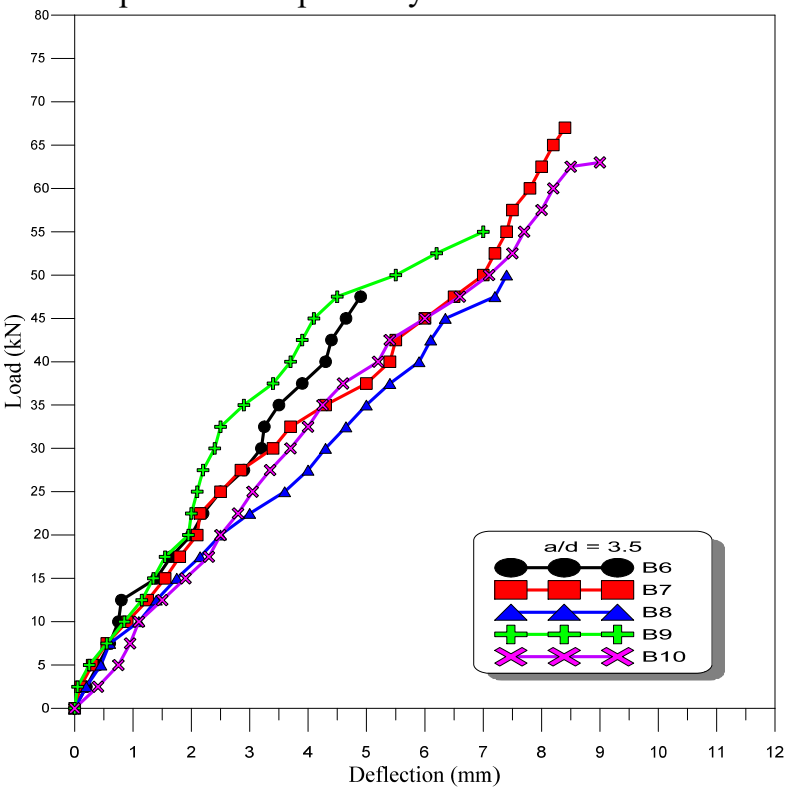

Figure (7) load-deflection curves for Group 2

\section{9-3 Failure Modes and Crack Pattern}

All the tested wide beams were failed by shear as shown in Fig. (8). The crack pattern at failure stages for all tested wide beams are of the same overall shape and propagation way with various widths. Except wide beam B6, the crack width in the Group 2 is less than crack width in the Group 1. 

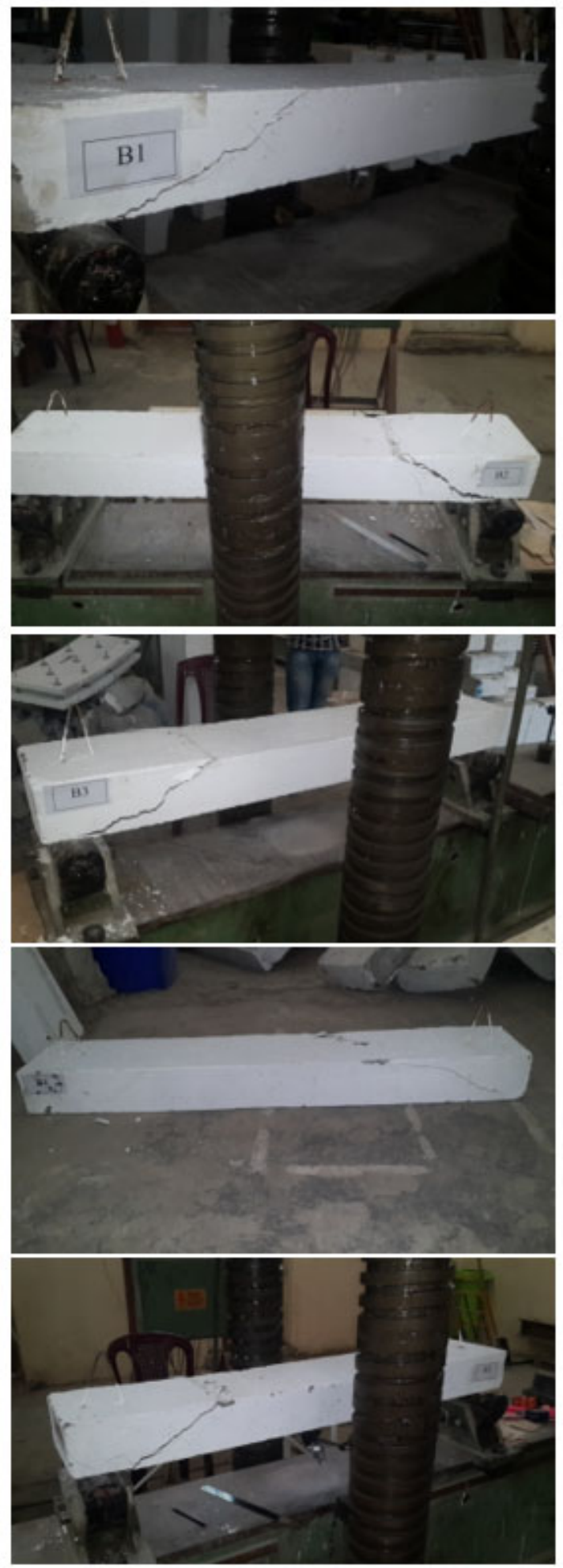

Figure (8) Shear crack pattern in the tested wide beams

\section{9-4 Effect of high strength concrete in full wide beams}

When using high strength concrete as a full mix in wide beam (B2) and (B7), the cracking and ultimate load were increased in both groups in comparison with wide beams (B1 and B6) respectively which they made of normal strength concrete. For wide beam (B2), the increasing in cracking load is about $(116 \%)$ and about $(42.8 \%)$ in ultimate load in comparison with wide beam (B1). For wide beam (B7), the increasing in cracking load is (85.7\%) and about $(41 \%)$ in ultimate load in comparison with wide beam (B6). The using of high strength concrete affect the deflection values also, For wide beam (B2), the increasing in cracking deflection is about (159.26\%) and about 
$(82.25 \%)$ in ultimate deflection in comparison with wide beam (B1). For wide beam (B7), the increasing in cracking deflection is (152.3\%) and about $(71.42 \%)$ in ultimate deflection in comparison with wide beam (B6).

Figures (9 and 10) illustrate the load-deflection curves for (B1 and B2) and (B6 and B7) respectively.

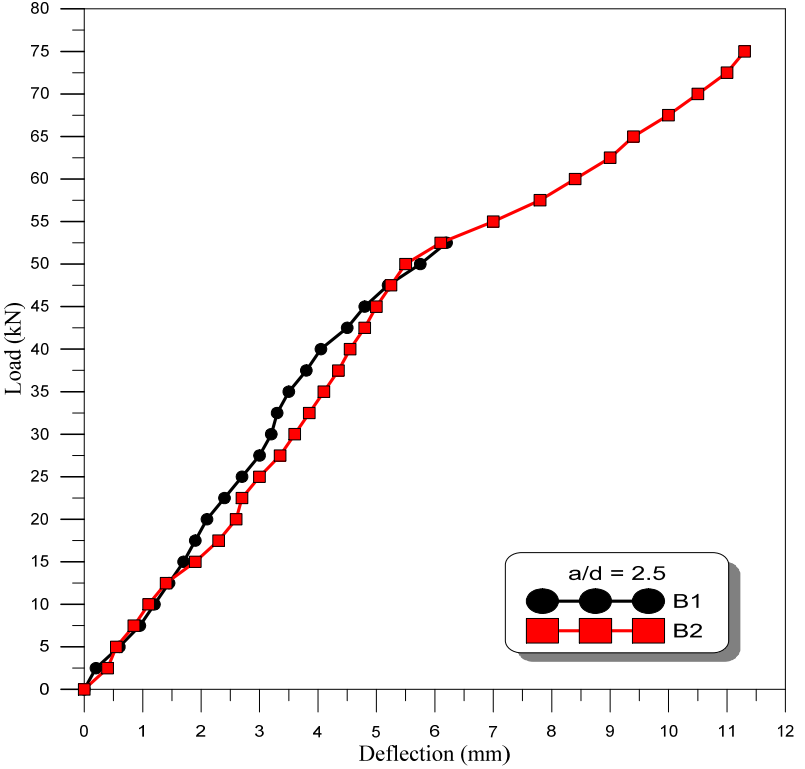

Figure (9) load-deflection curves for (B1 and B2)

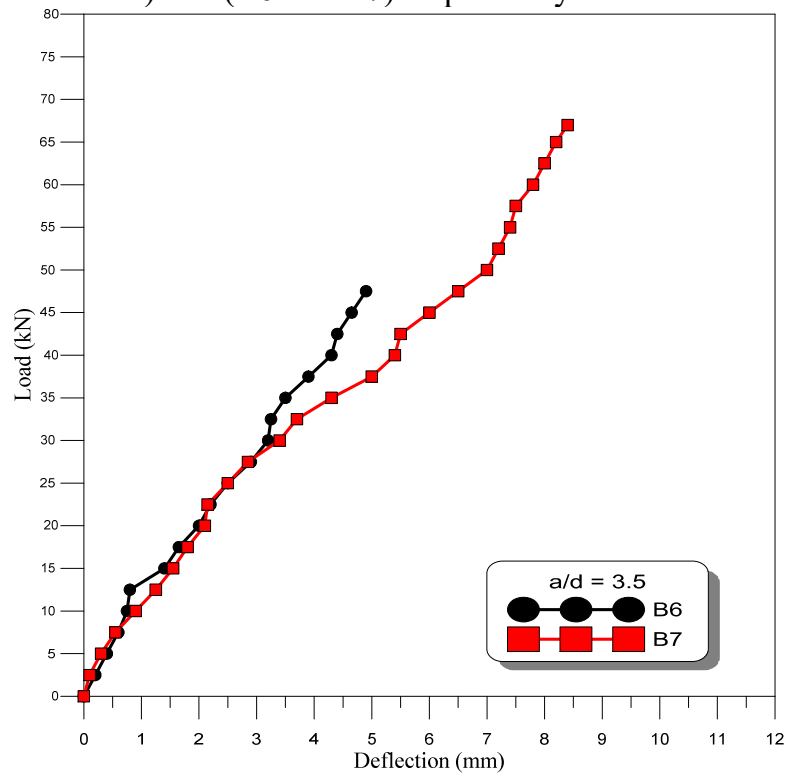

Figure (10) load-deflection curves for (B6 and B7)

9-5 Effect of high strength concrete in bottom of wide beams

When the high strength concrete is in the bottom of wide beam (B3) and (B8), the cracking and ultimate load were increased in both groups in comparison with wide beams (B1 and B6) respectively. For wide beam (B3), the increasing in cracking load is about (48\%) and about (8.57\%) in ultimate load in comparison with wide beam (B1). For wide beam (B8), the increasing in cracking load is $(42.86 \%)$ and about $(5.26 \%)$ in ultimate load in comparison with wide beam (B6). For wide beam (B3), the increasing in cracking deflection is about (11.11\%) and about $(19.35 \%)$ in ultimate deflection in comparison with wide beam (B1). For wide beam (B8), the increasing in cracking deflection is (104.76\%) and about (51.02\%) in ultimate deflection in comparison with wide beam (B6).

Figures (11 and 12) show the load-deflection curves for (B1 and B3) and (B6 and B8) respectively.

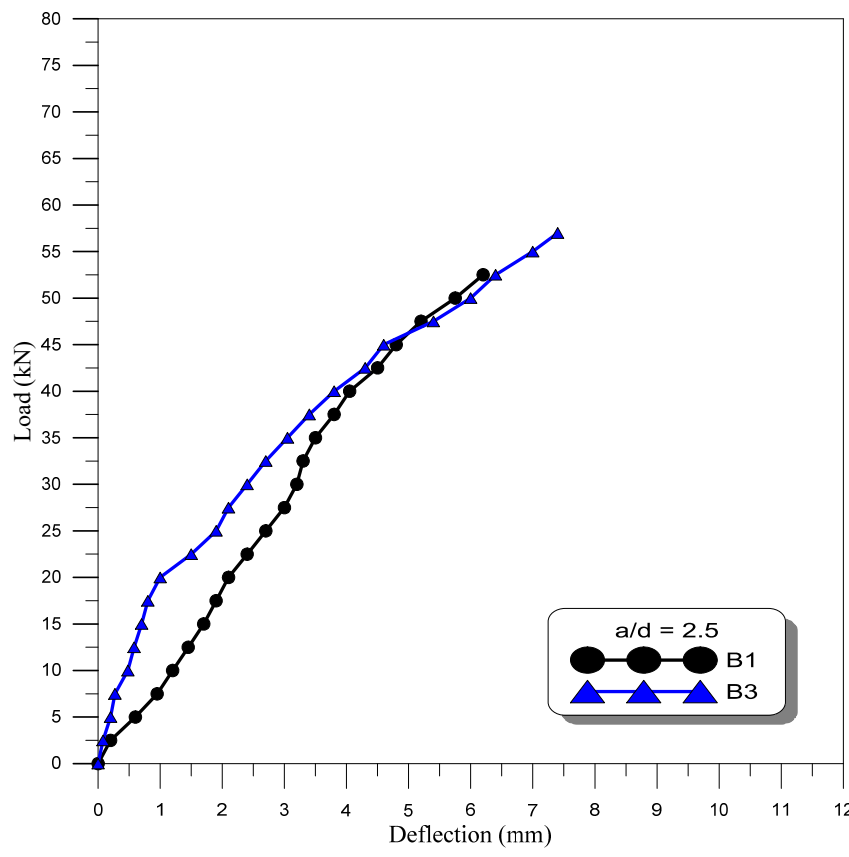

Figure (11) load-deflection curves for (B1 and B3)

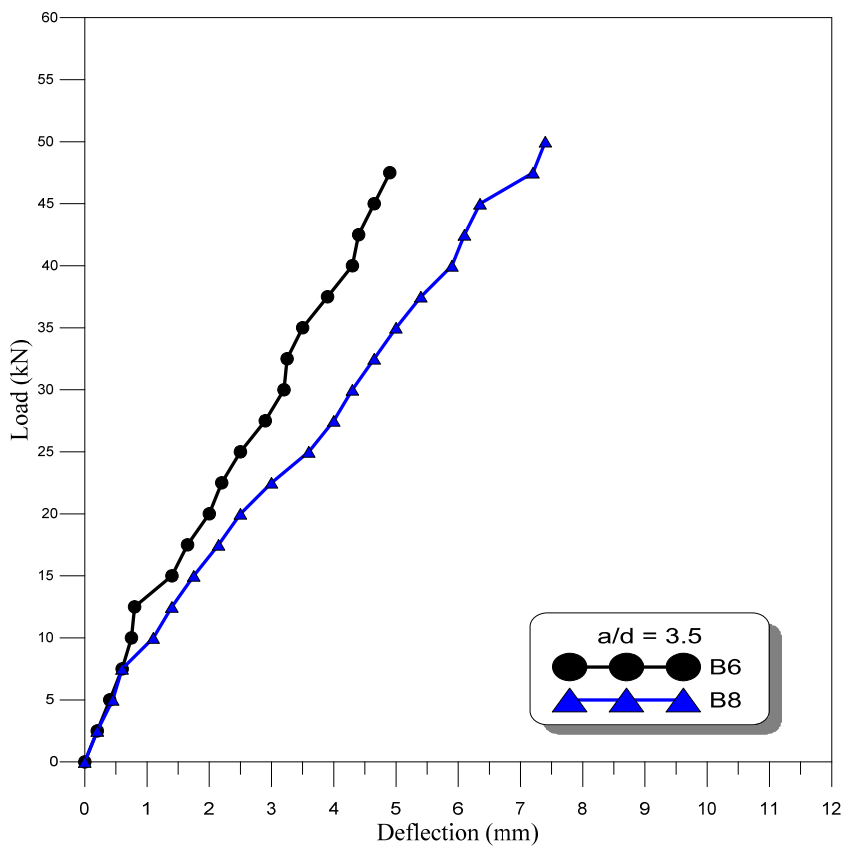

Figure (12) load-deflection curves for (B6 and B8) 
9-6 Effect of high strength concrete in top of wide beams

When casting the high strength concrete in the top of wide beam (B4) and (B9), the cracking and ultimate load were increased in both groups in comparison with wide beams (B1 and B6) respectively. For wide beam (B4), the increasing in cracking load is about $(84 \%)$ and about $(19.04 \%)$ in ultimate load in comparison with wide beam (B1). For wide beam (B9), the increasing in cracking load is $(66.66 \%)$ and about $(15.79 \%)$ in ultimate load in comparison with wide beam (B6). For wide beam (B4), the increasing in cracking deflection is about (59.26\%) and about (27.42\%) in ultimate deflection in comparison with wide beam (B1). For wide beam (B9), the increasing in cracking deflection is (38.09\%) and about (42.86\%) in ultimate deflection in comparison with wide beam (B6). Figures (13 and 14) show the load-deflection curves for (B1 and B4) and (B6 and B9) respectively.

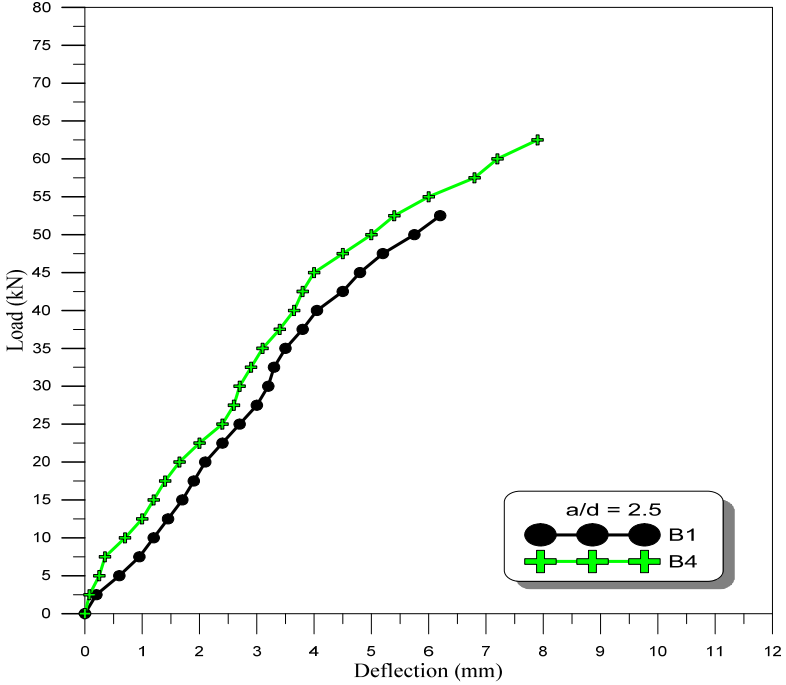

Figure (13) load-deflection curves for (B1 and B4)

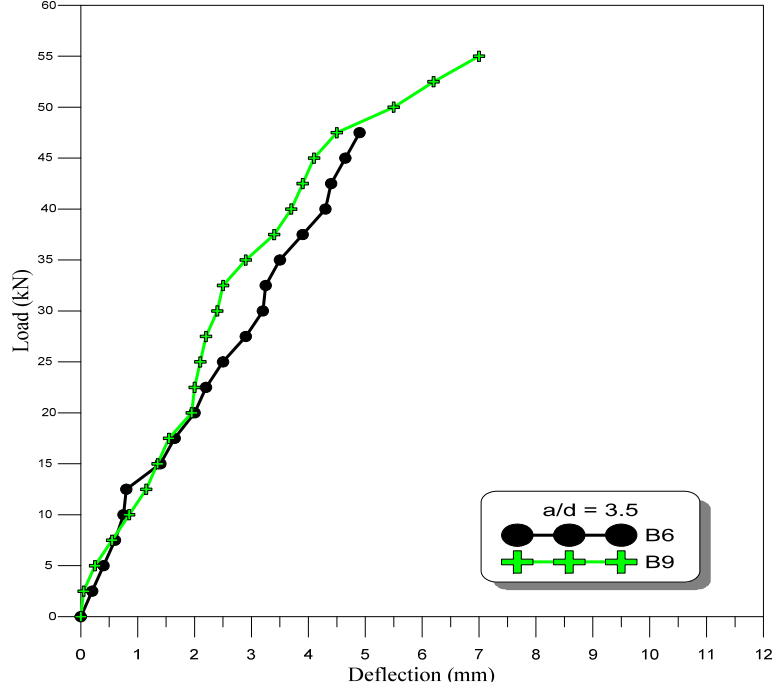

Figure (14) load-deflection curves for (B6 and B9)

\section{9-7 Effect of high strength concrete in the sides of wide beams}

When putting the high strength concrete in the sides of wide beam( each beam was divided into three zones of equal length $(400 \mathrm{~mm})$ along its longitudinal axis) as in case of (B5) and (B10), the cracking and ultimate load were increased in both groups in comparison with wide beams (B1 and B6) respectively. For wide beam (B5), the increasing in cracking load is about (104\%) and about $(33.33 \%)$ in ultimate load in comparison with wide beam (B1). For wide beam (B10), the increasing in cracking load is (78.57\%) and about (32.63\%) in ultimate load in comparison with wide beam (B6). For wide beam (B5), the increasing in cracking deflection is about (100\%) and about $(38.71 \%)$ in ultimate deflection in comparison with wide beam (B1). For wide beam (B10), the increasing in cracking deflection is (119.04\%) and about (83.67\%) in ultimate deflection in comparison with wide beam (B6). Figures (15 and 16) show the load-deflection curves for (B1 and B4) and (B6 and B9) respectively.

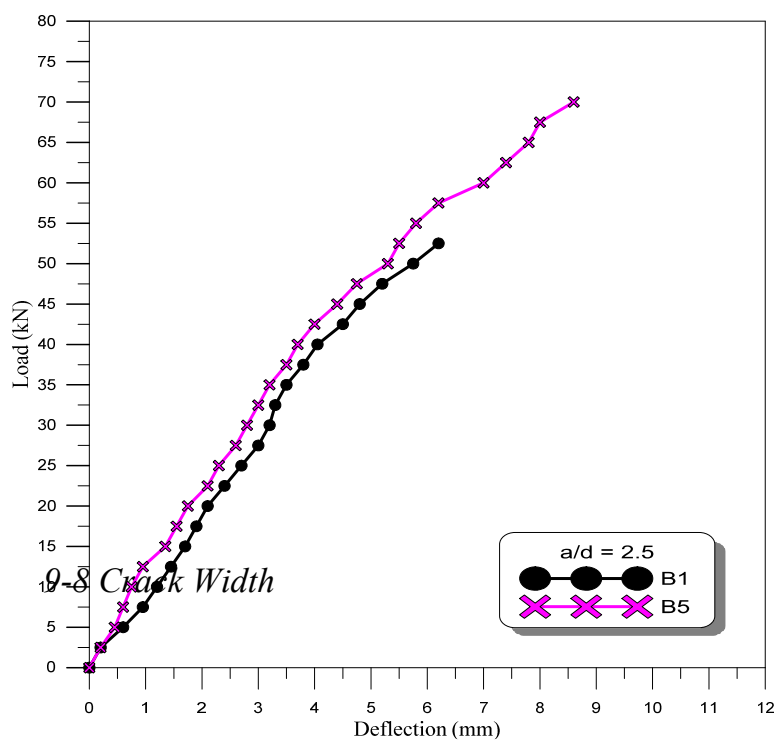

Figure (15) load-deflection curves for (B1 and B5)

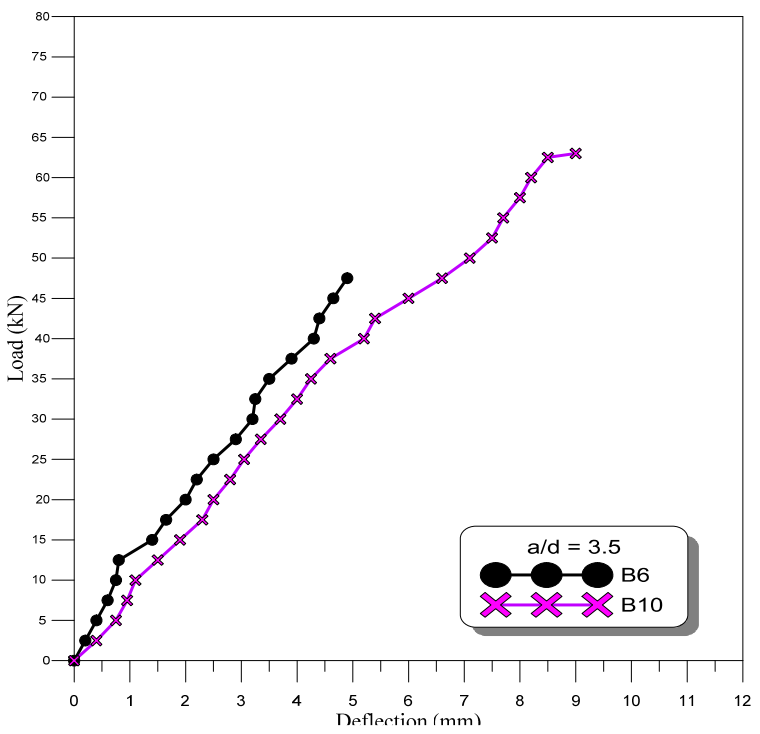

Figure (16) load-deflection curves for (B6 and B10) 
One of the serviceability requirements is crack width of concrete different members therefore, it is must be observed and checked with the allowable limits recorded in the standards and codes of practice. In the present research work, crack width was measured at cracking and ultimate stages. The GAOSUO Digital Microscope was used for reading the crack width of the tested wide beams which is a slim type tool and can be easily used in different fields. The most important specifications are: Image CMOS sensor, focus range 0mm $\sim 40 \mathrm{~mm}$, snap shot software and hardware, video capture resolution $0.3 \mathrm{M}$, built-in 8 white-light LED and adjustable illumination ensure the magnified images are clear and bright, still image capture resolution $640 * 480$, frame rate $30 \mathrm{f} / \mathrm{s}$ under 600 LUX brightness, digital zoom $5 \mathrm{X}$ sequence mode, magnification range is $800 \mathrm{X}$.

\section{0 - Conclusions}

From the experimental program which made to investigate the shear effect of reinforced concrete hybrid wide beams, the main points can be concluded:

1- The increasing of shear span to depth $(\mathrm{a} / \mathrm{d})$ ratio from 2.5 to 3.5 reduces first cracking load. The reduction is larger when using high strength concrete in the tested wide beams. The observed maximum reduction is $(28 \%)$ was in wide beam (B7) in compared with wide beam (B2). The reduction was slightly decreases with using normal strength concrete in the samples.

2-The increasing of shear span to depth $(\mathrm{a} / \mathrm{d})$ ratio from 2.5 to 3.5 reduces ultimate load. The reduction is larger when using high strength concrete in this stage also. The observed maximum reduction is $(12.3 \%)$ was in wide beam (B8) in compared with wide beam (B3). The reduction was of the same range when using normal or high strength concrete in the tested beams.

3-The tested wide beams were failed by shear cracks mode. The cracks are of the same pattern and overall shape and propagation way with various widths. Except wide beam B6, the crack width in the Group 2 is less than those in the Group 1.

4-For wide beam (B2), the increasing in cracking load is about (116\%) and about (42.8\%) in ultimate load in comparison with wide beam (B1). For wide beam (B7), the increasing in cracking load is (85.7\%) and about (41\%) in ultimate load in comparison with wide beam (B6).

5 -For wide beam (B3), the increasing in cracking load is about (48\%) and about $(8.57 \%)$ in ultimate load in comparison with wide beam (B1). For wide beam (B8), the increasing in cracking load is (42.86\%) and about $(5.26 \%)$ in ultimate load in comparison with wide beam (B6).

6-For wide beam (B4), the increasing in cracking load is about (84\%) and about (19.04\%) in ultimate load in comparison with wide beam (B1). For wide beam (B9), the increasing in cracking load is $(66.66 \%)$ and about $(15.79 \%)$ in ultimate load in comparison with wide beam (B6).

7-For wide beam (B5), the increasing in cracking load is about (104\%) and about (33.33\%) in ultimate load in comparison with wide beam (B1). For wide beam (B10), the increasing in cracking load is (78.57\%) and about $(32.63 \%)$ in ultimate load in comparison with wide beam (B6).

8 -For wide beam (B2), the increasing in cracking deflection is about (159.26\%) and about (82.25\%) in ultimate deflection in comparison with wide beam (B1). For wide beam (B7), the increasing in cracking deflection is $(152.3 \%)$ and about $(71.42 \%)$ in ultimate deflection in comparison with wide beam (B6).

9-The increasing in cracking deflection for wide beam (B3) is about (11.11\%) and about (19.35\%) in ultimate deflection in comparison with wide beam (B1). For wide beam (B8), the increasing in cracking deflection is $(104.76 \%)$ and about $(51.02 \%)$ in ultimate deflection in comparison with wide beam (B6).

10 -In case of wide beam (B4), the increasing in cracking deflection is about $(59.26 \%)$ and about $(27.42 \%)$ in ultimate deflection in comparison with wide beam (B1). While for wide beam (B9), the increasing in cracking deflection is $(38.09 \%)$ and about $(42.86 \%)$ in ultimate deflection in comparison with wide beam (B6).

11 -For wide beam (B5), the increasing in cracking deflection is about (100\%) and about (38.71\%) in ultimate deflection in comparison with wide beam (B1). For wide beam (B10), the increasing in cracking deflection is $(119.04 \%)$ and about (83.67\%) in ultimate deflection in comparison with wide beam (B6).

\section{1-References}

1-Edward G. Sherwood, Adam S. Lubell, Evan C. Bentz, and Michael P. Collins "One-Way Shear Strength of Thick Slabs and Wide Beams" ACI Structural Journal, V. 103, No. 6, November-December 2006, pp. 794802.

2- S. E. Mohammadyan-Yasouj, A. K. Marsono, R. Abdullah, and M. Moghadasi" Wide Beam Shear Behavior with Diverse Types of Reinforcement" ACI Structural Journal, V. 111, No. 1-6, January-December 2014, pp $1-10$.

3. ACI Committee 318, "Building Code Requirements for Structural Concrete (ACI 318-08) and Commentary," American Concrete Institute, Farmington Hills, MI, 2008, pp 473.

4. EuroCode 2, "Design of Concrete Structures-Part 1-1" General Rules and Rules for Buildings (EN1992-1-1)," European Committee for Standardization, Brussels, Belgium, Dec. 2004, pp 451. 